\title{
Plantão de escuta: uma aplicação da Teoria Humanística no processo clínico de enfermagem
}

\author{
On-call listening: an application of Humanistic Theory in the clinical nursing process \\ Turno de escucha: una aplicación de la Teoría Humanista en el proceso clínico de enfermería
}

\author{
Alexandre Vicente da Silva'; Iraci dos Santos"; Célia Caldeira Fonseca Kestenberg'II'; Célia Pereira Caldas ${ }^{\prime V}$; \\ Lina Marcia Miguéis Berardinelliv; Lenilce Pereira de Souza da Silvavl
}

\begin{abstract}
RESUMO
Objetivo: refletir sobre a aplicabilidade do plantão de escuta fundamentado na Teoria Humanística no processo clínico de enfermagem. Método: reflexão teórica, realizada em 2016, sobre os metaparadigmas e pressupostos de Paterson e Zderad utilizados no atendimento de enfermagem em saúde mental aos residentes de enfermagem do Hospital Universitário Pedro Ernesto, Rio de Janeiro, Brasil, visando acolher, escutar e contribuir para experiências e vivências dessa teoria no plantão de escuta. Resultados: destacou-se a segunda fase do processo clínico - a enfermeira conhece intuitivamente o outro, considerada fase avaliativa e de intervenção, devido à relação dialógica e a compreensão empática presentes. Conclusão: a utilização da empatia, como veículo da compreensão e elaboração, ajuda o cliente atendido. Traz em si um potencial terapêutico proporcionando consolo, conforto, ampliação da compreensão de si, alivia a solidão, a ansiedade e eleva a autoestima. Sobretudo, ajuda a elaborar e encontrar um sentido na experiência vivida. Descritores: Enfermagem; teoria; empatia; cuidado.
\end{abstract}

\section{ABSTRACT}

Objective: to think about the applicability of a listening service based on humanistic theory in the clinical nursing process. Method: this theoretical reflection on the metaparadigms and assumptions of Paterson and Zderad used in mental health nursing care for nursing residents at the Pedro Ernesto University Hospital, in Rio de Janeiro, Brazil, with a view to welcoming, listening to and contributing to experiences of this theory in the listening service. Results: the second phase of the clinical process - in which the nurse intuitively knows the other - was most notable. This is a phase of evaluation and intervention, because of the dialogic relationship and empathic understanding involved. Conclusion: using empathy as a vehicle for understanding and elaboration helps clients of care. It embodies therapeutic potential, providing comfort, broadening self-understanding, alleviating loneliness and anxiety, and boosting self-esteem. Above all, it helps to elaborate and find meaning in lived experience. Descriptors: Nursing; theory; empathy; care.

\section{RESUMEN}

Objetivo: reflexionar sobre la aplicabilidad del turno de escucha fundamentado en la Teoría de enfermería humanística en el proceso clínico de enfermería. Método: reflexión teórica, realizada en 2016, sobre los metaparadigmas y presupuestos de Paterson y Zderad utilizados en la atención de enfermería en salud mental a los residentes de enfermería del Hospital Universitario Pedro Ernesto, Río de Janeiro, Brasil, con el objetivo de acoger, escuchar y contribuir a experiencias y vivencias de esa teoría en el turno de escucha. Resultados: se destacó la segunda fase del proceso clínico - la enfermera conoce intuitivamente al otro-, considerada fase evaluativa y de intervención, debido a la relación dialógica y la comprensión empática presentes. Conclusión: la utilización de la empatía, como vehículo de la comprensión y de la elaboración, ayuda al cliente atendido. Trae en sí un potencial terapéutico proporcionando consuelo, comodidad, ampliación de la comprensión de sí, alivio a la soledad, la ansiedad y elevación de la autoestima. Sobre todo, ayuda a elaborar y encontrar un sentido en la experiencia vivida.

Descriptores: Enfermería; teoría; empatía; cuidado.

\section{INTRODUÇÃO}

O plantão de escuta é uma modalidade de atendimento de enfermagem em saúde mental oferecido aos residentes de enfermagem do Hospital Universitário Pedro Ernesto da Universidade do Estado do Rio de Janeiro (HUPE/UERJ). Sua meta é acolher, escutar e contribuir na elaboração de experiências vividas destes residentes. Surgiu em 1990, sendo desdobramento do Projeto de extensão vivendo vivências da Faculdade de Enfermagem da UERJ, que desenvolve há 26 anos atividades vivenciais em grupo com graduandos do

'Enfermeiro. Professor. Doutorando do Programa de Pós-Graduação, Universidade do Estado do Rio de Janeiro. Brasil. E-mail: alexvicentesilva35@gmail.com "Professora Titular, Universidade do Estado do Rio de Janeiro. Brasil. E-mail: iraci.s@terra.com.br

I'Enfermeira. Professora Adjunta, Universidade do Estado do Rio de Janeiro, Brasil. E-mail celiaprofuerj@gmail.com

IVEnfermeira. Professora Associada, Universidade do Estado do Rio de Janeiro. Brasil. E-mail: celpcaldas@gmail.com

vEnfermeira. Professora Associada, Universidade do Estado do Rio de Janeiro. Brasil. E-mail: I.m.b@uol.com.br

"Enfermeira. Mestre pelo Programa de Pós-Graduação em Enfermagem, Universidade do Estado do Rio de Janeiro. Brasil. E-mail: lenilcep.silva@gmail.com 
último período acadêmico, tendo como objeto de saber - acolher as demandas emocionais do aluno, pois alguns estudantes solicitavam atendimento individual. Assim, surgiu o Plantão de escuta.

Desde 2014, após as solicitações da coordenação da residência de enfermagem, esse atendimento foi implantado no HUPE/UERJ, visando avaliar e atender as demandas emocionais de alguns residentes. Os encontros individuais, com duração de 60 minutos, passaram a acontecer no consultório de enfermagem do ambulatório de saúde mental. Ao longo dos atendimentos, verificou-se a necessidade de um referencial teórico que fundamentasse o processo clínico que ali se estabelecia.

A partir daí, formulou-se a questão orientadora: qual teoria de enfermagem será capaz de dar suporte ao plantão de escuta? Teve-se como pressuposto: o encontro, a relação dialógica e a presença, propostos pela Teoria Humanística de Enfermagem, fundamentam teoricamente o processo clinico vivido nos atendimentos do plantão de escuta.

Tal pressuposto se aproximava muito do trabalho que estava sendo realizado. Desse modo, foi possível caracterizar o atendimento dentro do âmbito da enfermagem, com conceitos validados, próprios da profissão e facilitadores da construção dos objetivos terapêuticos.

Diante do exposto, elaborou-se o objetivo: refletir sobre a aplicabilidade do plantão de escuta fundamentado na Teoria Humanística de Enfermagem, no processo clínico de enfermagem.

\section{ReferenCIAL TEÓRICO-METOdológico}

A Teoria Humanística de Enfermagem surgiu em 1976, a partir das vivências de Paterson e Zderad na docência e no atendimento de enfermagem em psiquiatria e saúde mental. Seu conteúdo revela a influência da filosofia existencialista para compreender a vida, seu significado e as possibilidades de escolhas do humanismo, tentando uma visão ampla do potencial humano e da fenomenologia, buscando o significado do vivido na perspectiva da própria pessoa. Percebe-se a influência dessas correntes de pensamento mediante a ênfase que as autoras dão ao significado da vida como ela é vivida, a natureza do diálogo e a importância do campo perceptivo. Elas propõem que essa profissão seja desenvolvida como uma experiência existencial ${ }^{1}$.

\section{Compreensão dos metaparadigmas da teoria}

Seres humanos - vistos como uma estrutura existencial de vir-a-ser, através de escolhas. È um ser individual, relacionando-se com outros no tempo e no espaço. A existência humana depende da coexistência ${ }^{1}$.

Saúde - entendida como uma questão de sobrevivência pessoal. É mais que a ausência de doença. Os indivíduos possuem o potencial para a estabilidade, um estar melhor, tornar- se tudo que é humanamente possível. Saúde é um processo de encontrar sentido na vida e é experiência no mundo vivido ${ }^{1}$.

Enfermagem - implica um encontro especial de pessoas. É uma resposta de cuidado de uma pessoa para a outra, num período de necessidade que visa ao desenvolvimento do bem-estar e do estar melhor. É um tipo de diálogo vivido com uma experiência intersubjetiva ${ }^{1}$.

Comunidade - São duas ou mais pessoas, lutando unidas o viver-morrer repentino. É através do partilhar intersubjetivo de significado, em comunidade, que seres humanos são confortados e cuidados. É onde acontecem as relações ${ }^{1}$.

\section{A Teoria Humanística mediante seus pressupostos}

Considera-se a enfermagem um diálogo vivido entre a enfermeira e o cliente; a partir dele são conciliadas razão e sensibilidade, objetividade e subjetividade, o zelar e o confortar no ato de cuidar. O diálogo se caracteriza por um relacionamento criativo e nele estão envolvidos ${ }^{1}$ :

Encontro - reunião de seres humanos. Caracteriza-se pela expectativa de que haverá uma enfermeira e alguém para ser atendido. Nesse encontro alguns fatores influenciam tais como: sentimentos surgidos, a singularidade dos participantes e a decisão de revelar-se para o outro e conter-se com o outro ${ }^{1}$.

Relacionar-se - refere-se ao processo de estar com o outro, e ocorre de duas maneiras: quando nos relacionamos como sujeito com um objeto, conhecem outros através de: abstrações, conceituações, categorizações e rótulos. A outra maneira é o relacionamento entre pessoas. Nessa forma de relação é possível conhecer a pessoa em sua individualidade única. A relação eu - tu possibilita desenvolver esse potencial único ${ }^{2}$. Ambos os relacionamentos são fundamentais para o processo clínico de enfermagem.

Estar presente - qualidade de estar aberto, receptivo, pronto e disponível à outra pessoa de modo recíproco. Abrir-se à experiência de enfermagem. Muitas vezes torna-se um comportamento de difícil alcance ${ }^{1}$.

O chamado e a resposta - constituem uma indicação da natureza complexa do diálogo vivido. São transacionais, sequenciais e simultâneos. Enfermeiras e clientes chamam e respondem um ao outro dentro de uma estrutura de tempo e espaço. Acontece de modo verbal e/ou não ${ }^{1}$.

Propósito da enfermagem - nutrir o bem-estar e o estar - melhor das pessoas. Esse nutrir é a habilidade de participar em situações de enfermagem e de se esforçar com os outros nas suas experiências de saúde e de sofrimento para a atualização do seu potencial ${ }^{1}$.

Ajuda no cuidar - a enfermeira ajuda o cliente a tornar-se melhor em sua situação particular. A prática da enfermagem e sua fundamentação teórica estão interrelacionadas. Ser enfermeira é desenvolver essa 
prática como um ser humano que sente, valoriza, reflete e conceitua. Do cotidiano dessa profissão surge o conjuntoorganizado do conhecimento clínico ${ }^{1}$.

\section{MÉTODO}

Reflexão teórica, realizada em 2016, sobre os metaparadigmas e pressupostos de Paterson e Zde$\mathrm{rad}^{1}$, utilizados no atendimento de enfermagem em saúde mental aos residentes de enfermagem do HUPE/ UERJ - Rio de Janeiro - Brasil, visando acolher, escutar e contribuir para experiências e vivências dessa teoria no plantão de escuta. O método apresenta cinco fases:

Preparação para o conhecimento - a enfermeira busca o autoconhecimento e, neste processo, corre o risco de confrontar-se com sua possível incapacidade de se perceber e de tornar seus pensamentos e atitudes mais humanas ${ }^{3}$.

A enfermeira conhece intuitivamente o outroimporta o conhecimento que se tem do outro, o modo como vive e vê seu mundo. Procura se introduzir no tempo, ritmo e mobilidade do outro, levando a um conhecimento absoluto, intuitivo, inexpressável único do outro. Ela responde à singularidade do cliente, não se impõe, mantém sua capacidade de surpresa, questionamento e presença autêntica ${ }^{3}$.

Conhecimento científico do outro - após vivenciá-lo intuitivamente, conceitua-se a experiência e a expressa segundo o seu potencial humano. Um momento de refletir, analisar, classificar, comparar, contrastar, relacionar, interpretar, denominar e categorizar autêntico ${ }^{3}$.

A enfermeira sintetiza de forma complementar as realidades conhecidas - momento de comparar e sintetizar as múltiplas realidades conhecidas para ter uma visão ampliada. Como conhecedora, estabelece relações entre essas realidades e então as interpreta, seleciona e classifica ${ }^{3}$.

Sucessão interna da enfermeira do múltiplo para a unidade paradoxal- através de reflexões e considerações sobre as relações entre as múltiplas visões, a enfermeira faz uma revisão compreensiva e expande sua própria visão. Ela vai além das multiplicidades e contradições e chega a uma concepção importante para a maioria ou para todos ${ }^{3}$.

Ressalta-se que a metodologia de enfermagem fenomenológica não segue o processo de enfermagem convencional. Através da conceitualização e do compartilhamento a metodologia permite um avanço no processo de construção do conhecimento originado do mundo vivido dessa profissão. O método utiliza uma abordagem sistemática de interação com o cliente ${ }^{3}$. No plantão de escuta, deu-se ênfase a segunda fase do método proposto da enfermagem fenomenológica. As autoras referem esta fase como sendo um momento de avaliação. Entretanto, entende-se que ele também é um momento de intervenção, pois é neste momento que ocorre a escuta e a compreensão empática.

\section{RESUltados E Discussão}

No plantão de escuta, trabalha-se com o emergente. Inexiste uma agenda estabelecida previamente com dias marcados neste primeiro momento. A coordenação da residência faz um contato telefônico, encaminhando o residente para o atendimento no plantão de escuta. O momento da busca de ajuda é muito importante, pois o cliente está motivado e em franco movimento de elaboração da sua experiência vivida e não deve ser interrompido ${ }^{4}$. Este movimento destaca a necessidade de o enfermeiro ter disponibilidade interna, prontidão e abertura para estar diante do inesperado, ao atender essa pessoa. Lidar com o imprevisível é o grande desafio do enfermeiro ao atender os residentes no plantão de escuta. A relação de ajuda se dá no momento presente, no aqui e agora. A consciência deste limite temporal potencializa o atendimento, favorece a elaboração da experiência vivida e facilita processos já iniciados ${ }^{4}$. Ao chegar ao atendimento, o cliente traz uma queixa que pode ser angústia, estresse, ansiedade, dúvidas, tristeza, ansiedade, um mal-estar, uma circunstância difícil na vida ${ }^{5,6}$. É aí que começa o valioso trabalho da escuta sensível ${ }^{7-9}$.

O que o enfermeiro escuta quando escuta o outro? A escuta não é uma ação passiva. Ao escutar, o enfermeiro se disponibiliza a prestar atenção e ouvir sensivelmente o significado do movimento que a pessoa está fazendo. Escutar é uma forma de intervenção que facilita ao outro sua tomada de posição a partir de alguma clarificação em si mesmo ${ }^{7-9}$. É um convite à atenção a si mesmo, ao modo como pronuncia as palavras, ao peso que dá a certos sentimentos como angústias e desejos. A escuta pode ser uma forma de ser presença quando acolhe, ressoa, silencia, mas, sobretudo, quando acompanha o tempo, ritmo e o movimento do cliente $\mathrm{e}^{7,9}$. Ela começa mesmo antes do cliente começar a falar e está assentada na aceitação, numa presença silenciosa, assim como num ouvir profundo. Escutar é, também, dar início ao processo da compreensão empática. Empatia e compreensão são duas das essências (valores e crenças) presentes no processo clínico de enfermagem humanística ${ }^{1}$. Empatia pode ser definida como a capacidade de se colocar no lugar do outro, compartilhando seu modo de estar numa situação, resultando em um conhecimento profundo da sua perspectiva ${ }^{1,9}$.

Alguns estudos têm evidenciado os benefícios do uso da empatia através da tomada de perspectiva da outra pessoa tais como:ativação de sentimentos de compaixão, simpatia, consideração pelo estado de outra pessoa. Possibilita a construção de vínculo, a resolução de conflitos interpessoais, ajuda a reduzir sentimentos de raiva e mágoa, permite perdoar, ajudar, negociar, consolar e validar a perspectiva do outro ${ }^{6}$. Tendência a reduzir tensões, promove uma escuta sensível, contribui com um esforço consciente para entender as razões e sentimentos de outra pessoa ${ }^{7-10}$. 
Na enfermagem humanística, não cabe ao enfermeiro pensar sobre o cliente, mas pensar junto com ele, de modo que ambos possam caminhar juntos pelo mundo das experiências vividas do cliente, buscando sempre compreendê-lo empaticamente. A enfermagem é um diálogo vivenciado. É um modo criativo de relacionamento enfermeira/cliente. Dentro do diálogo ocorre o encontro, que é a reunião de seres humanos e há a expectativa de que haverá uma enfermeira e alguém para ser atendido ${ }^{1}$. É destacado neste encontro a habilidade empática como recurso capaz de impulsionar o processo compreensivo da pessoa, 911,12 . O desenvolvimento de uma escuta cuidadosa, atenta e sem julgamento visa a construção de uma relação diferenciada, dialógica, que abra caminho para uma relação do tipo $\mathrm{Eu}-\mathrm{Tu}^{2}$, como um encontro verdadeiro ${ }^{1}$.

A partir da companhia e compartilhamento verdadeiro do enfermeiro, o cliente pode arriscar-se a mergulhar no seu próprio processo e examinar suas experiências. Elas serão acolhidas e acompanhadas pelo enfermeiro que, estando presente e sensivelmente atento, poderá contribuir para a sua compreensão, indo além delas ${ }^{1}$. Nesse momento de imersão, o enfermeiro precisa entrar na relação e não deixar a pessoa sozinha com sua própria experiência. É preciso permanecer com ela diante da dor que foi escolhida para lhe ser apresentada e ter a coragem de explorar essa dor junto com ele ${ }^{13}$.

Através da escuta, da atenção, da presença, da aceitação e da empatia, comunica-se ao cliente que vale a pena examinar a experiência, o sofrimento, a angústia, a contradição, os desafios e responder a própria vida. Dessa forma, ele estará se possibilitando entrar em contato consigo mesmo e encontrando um sentido na experiência vivida. Assim, o cliente se movimenta e caminha na busca de maior clareza e integração de si, colocando-se, desse modo, em devir. Este movimento reflexivo e vivencial tem como resposta a apropriação de um saber sobre $\mathrm{si}^{1,13,14}$. 0 encontro empático funciona como um potente recurso que contribui para a apreensão intuitivada essência do ser, ajuda na busca do significado da experiência vivida e compreende o mundo vivido ${ }^{1}$.

Ter o mundo vivido do cliente, como o foco das experiências de enfermagem, significa focalizar a realidade primária da experiência imediata, o mundo das significações, tal como se apresenta. Isto ocorre através da empatia onde é possível penetrar no mundo perceptual do outro, tomando a perspectiva de como este outro vivencia o mundo, sente e percebe as experiências ${ }^{1,10} \mathrm{~A}$ empatia possibilita que o enfermeiro não somente penetre no mundo do cliente, mas permite também que ele se mova na companhia dele, buscando a compreensão da sua experiência vivida.

É possível, ainda, que nesta caminhada da relação terapêutica, o enfermeiro consiga perceber, no mundo vivido do cliente, alguns aspectos que ele mesmo não tinha conseguido ver ainda. Quando a compreensão empática pode de fato ser efetivada e se apreender a vivência do que ocorre no mundo interior do cliente, de como ele a sente, a vê e isso é verbalizado, então a mudança pode ocorrer ${ }^{12,14,15}$.

Na enfermagem humanística não há preocupação com uma mudança de comportamento, mas sim com o significado atribuído à experiência vivida pelo cliente. Poderá haver uma mudança na perspectiva que o cliente tem da sua experiência, assumir responsabilidade por suas escolhas e conseguir encontrar sentido para a vida. Fazendo isso com uma enfermeira, ele terá a oportunidade de confirmar o humano da situação e da sua própria perspectiva, o que resultaria em crescimento pessoal, em um estar melhor ou em bem-estar ${ }^{1,15-18}$. Um desejo contínuo de compreender de modo empático a experiência da pessoa pode ser extremamente significativo e formador de vínculo para a relação terapêutica enfermeiro/ cliente e facilitar a elaboração da experiência vivida.

\section{CONCLUSÃo}

O objetivo do estudo foi alcançado, pois houve reflexão sobre a utilização da Teoria Humanística de Enfermagem, fundamentando as ações do plantão de escuta. O segundo momento da metodologia de enfermagem humanística - a enfermeira conhece intuitivamente o outro, referido como um momento de avaliação, permite ressaltar que este também pode ser considerado como intervenção e produz resultados terapêuticos.

A empatia, como veículo da compreensão fenomenológica, ajuda o cliente a sentir-se compreendido e aceito. Traz em si um potencial terapêutico quando proporciona, consolo, conforto, ampliação da compreensão de si, alivia a dor, solidão, ansiedade, eleva a autoestima, ajudando a elaborar e encontrar um sentido na experiência vivida.Uma contribuição deste trabalho refere-se à descoberta de que a aplicação dos pressupostos humanísticos ajuda a agregar valor ao processo clínico de enfermagem e favorece o exercício da autonomia do enfermeiro.

\section{REFERÊNCIAS}

1. Paterson JE, Zderad LT. Enfermería humanística. México: Limusa; 1979.

2. Buber M. Eu e Tu.10ạ ed. São Paulo: Editora Centauro; 2012.

3. Praeger SG, Hogart CR, Paterson JE, Zderad. Teoria humanística de enfermagem. In: George JB. Organizador. Teorias de enfermagem. Porto Alegre (RS): Artes Médicas; 2000. p. 242-52.

4. Amatuzzi, MM. Por uma psicologia humana. 4a ed. Campinas (SP): Alínea; 2014.

5. Silva DSD, Tavares NVS, Alexandre ARG, Freitas DA, Breda $M Z$, Albuquerque MCS et al. Depressão e risco de suicídio entre profissionais de enfermagem: revisão integrativa. Rev. Esc. Enferm. USP. 2015 [citado em 10 ago 2017]; 49 (6): 1023-31. Disponível em: http://www.scielo.br/scielo.php?pid=S0080$-62342015000601023 \&$ script=sci_arttext\&tlng=pt

6. Albuquerque MCS, Zeviane BM, Basto MLA, Silva VMS, Tavares 
NVS. A atuação do enfermeiro com a pessoa em situação de suicídio: análise reflexiva. Rev. enferm. UFPE online 2017 [citado em 10 ago 2017]; 11 (2): 742- 8. Disponível em: https://periodicos.ufpe. br/revistas/revistaenfermagem/article/viewFile/11995/14564

7. Maynart WHC, Albuquerque MCS, Breda MZ, Jorge JS. A escuta qualificada e o acolhimento na atenção psicossocial. Acta Paul. Enferm. (Online) 2014 [ citado em 20 ago 2017]; 27 (4): 300- 4. Disponível em:http://www.scielo.br/scielo.php?pid=S0103$-21002014000400003 \&$ script=sci_abstract\&tlng=pt

8. Souza E, Farias EM. Plantão psicológico: a urgência da acolhida. In: Souza S, Filho FB, Montenegro LAA, organizadores. Plantão psicológico: resignificando o humano na experiência da escuta e do acolhimento. Curitiba (PR): CRV; 2015. p. 15-32.

9. Falcone EMO. O papel da tomada de perspectiva na experiência da empatia. In: Falcone EMO, Oliva $A D$, Figueiredo $C$, organizadores. Produções em terapia cognitivo comportamental. São Paulo: Casa do Psicólogo; 2012. p. 61-9.

10. Krznaric R. O poder da empatia: arte de se colocar no lugar do outro para transformar o mundo. Rio de Janeiro: Zahar; 2015. 11. Goleman D. Foco. A atenção e seu papel fundamental para o sucesso. Rio de Janeiro: Objetiva; 2014.

12. Tassinari MA, Durange WT. Experiência empática: da neurocioência à espiritualidade. Revista da Abordagem Gestáltica - Phenomenological Studies. 2014 [citado em 10 ago 2017]; 20 (1): 53-60. Disponível em:http://www.academia. edu/12628726/Experi\%C3\%AAncia_Emp\%C3\%A1tica_da_ Neuroci\%C3\%AAncia_\%C3\%A0_Espiritualidade
13. Albuquerque MCS, Breda MZ, Maynart, Silva DSD, Moura ECM. Relacionamento interpessoal entre usuários e profissionais de saúde na atenção psicossocial. Cogitare enferm. Rev. 2016 [citado em 10 ago 2017]; 21(9):1-9. Disponível em: http://revistas.ufpr. $\mathrm{br} /$ cogitare/article/view/46528

14. Fontgalland RC, Moreira V. Da empatía à compreensão empática: evolução do conceito no pensamento de Carl Rogers. Memorandum.2012 [citado em 10 ago 2017]; 23(3):32-56. Disponível em: http://www.fafich.ufmg.br/memorandum/revista/ wp-content/uploads/2012/11/fontgallandmoreira01.pdf.

15. Gomes ATL, Araújo JNM, Delgado MF, Lopes LA, Menezes DJC, Vitor AF. Aplicattion of the theory of Paterson and Zderad as systematization of nursing care. J. Nurs. UFPE on line. 2014 [cited 2017 Aug 20]; 8(6):1709-16. Available from: http://www. revista.ufpe.br/revistaenfermagem/index.php/revista/article/ viewFile/5973/pdf_5323.

16. Kestenberg CCF, Rosall BMS, Silva AV, Fabri JMD, Regazi ICR. Estresse em estudantes de enfermagem. Rev. enferm. UERJ. 2017 [citado em 10 ago 2017]; 25:e26716. Disponível em: http:// www.e-publicacoes.uerj.br/index.php/enfermagemuerj/article/ viewFile/26716/22358

17. Santos I, Silva LPS, Pacheco STA, Moreira MC, Silva LA, Silva AV. Autopercepção dos enfermeiros sobre a sua comunicação de notícias difíceis aos clientes hospitalizados. Rev. enferm. UERJ. 2017; 25: e 30003. 18. Santos ROJFL, Teixeira ER, Cursino EG. Estudos sobre as relações humanas interpessoais de trabalho entre os profissionais de enfermagem: revisão integrativa. Rev. enferm. UERJ. 2017; 25: e 26393 